\section{Heilpraktiker, eine Gefahr für die Bevölkerung?}

Die einzige fachliche Hürde bei der Erlaubniserteilung zur Ausübung des Heilpraktikerberufes ist die Überprüfung durch die Gesundheitsämter. Diese ist keine allgemeine Fachprüfung, sondern negativ definiert: „Die Erlaubnis wird nicht erteilt, ... wenn sich aus einer Überprüfung der Kenntnisse und Fähigkeiten des Antragstellers durch das Gesundheitsamt ergibt, dass sich durch die Ausübung der Heilkunde durch den Betreffenden eine Gefahr für die Volksgesundheit ergeben würde.“

— Eine lesenswerte Analyse von Heilpraktikerüberprüfungen in Frankfurt und Groß-Gerau im Zeitraum von 2004-2007 zeigt, dass 53\% der Anwärter die beliebig oft wiederholbaren Tests nicht bestehen. Ferner wird berichtet, dass 79\% der Hygienekontrollen in Heilpraktikerpraxen ergaben, dass kein Hygieneplan vorhanden war. In $49 \%$ der Fälle fehlte ein Reinigungs- und Desinfektionsplan, und in $60 \%$ der Praxen fehlten Händedesinfektionsspender.

Die Autoren kommen zu einer vernichtenden Schlussfolgerung: „Die derzeitigen gesetzlich geregelten Überprüfungen der Heilpraktikeranwärter können keinen ausreichenden Schutz der Bevölkerung bieten“.

\section{Kommentar}

Der Beruf des Heilpraktikers ist ein weitgehend deutsches Phänomen. Er ist in Deutschland staatlich geregelt, aber nicht staatlich anerkannt. Derzeit praktizieren in Deutschland über 23 ooo Heilpraktiker. Nur etwa $17 \%$ von ihnen besuchten eine Heilpraktikerschule länger als zwei Jahre. Viele Heilpraktiker wenden invasive Methoden an wie z. B. Infusionen, Eigenbluttherapie oder Akupunktur. Vor diesem Hintergrund sind die hier berichteten Daten ernüchternd, vielleicht sogar beängstigend.

E. ERNST -

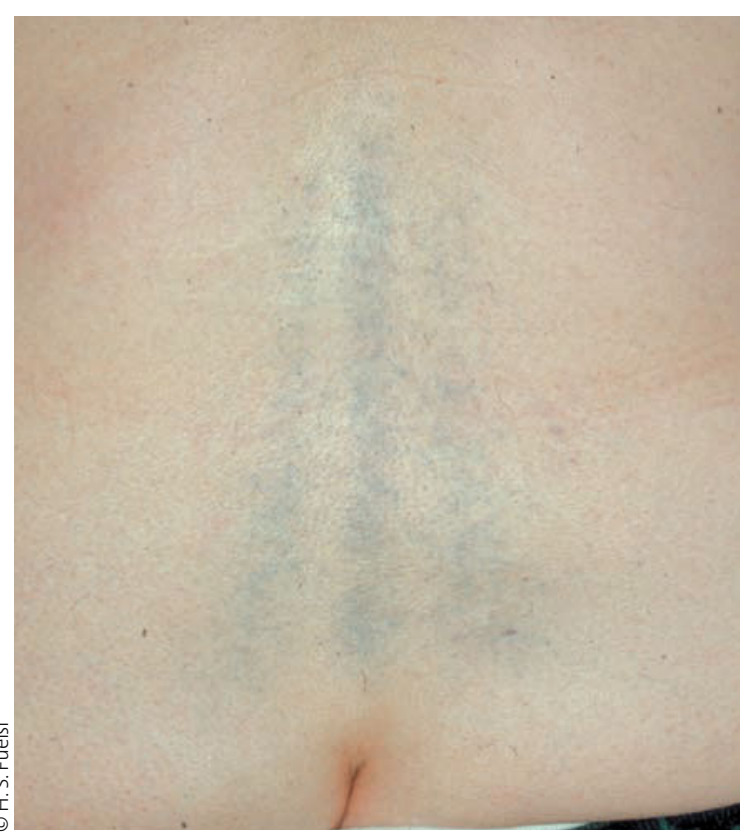

Hämatome nach Behandlung beim Heilpraktiker.

\begin{abstract}
- U. Heudorf, A. Carstens, M. Exner Heilpraktiker und öffentliches Gesundheitswesen Gesetzliche Grundlagen sowie Erfahrungen aus den Überprüfungen der Heilpraktikeranwärter und der infektionshygienischen Überwachung von HeilpraktikerPraxen im Rhein-Main-Gebiet 2004-2007. Bundesgesundheitsblatt 2010; 53 (2):245-257, DOI: 10.1007/s00103-009-1024-0
\end{abstract}

\title{
Was hilft bei Schwangerschaftserbrechen?
}

\begin{abstract}
Ein internationales Team ging in einem Cochrane-Review der Frage nach, ob es Therapieformen gibt, die bei Schwangerschaftserbrechen erwiesenermaßen wirkungsvoll sind.
\end{abstract}

_ Es fanden sich insgesamt 27 Studien zu den unterschiedlichsten Interventionen bei Schwangerschaftserbrechen. Am besten war die Evidenz noch für die Akupressur. Doch auch hier war sie nicht wirklich überzeugend.
Alle anderen Behandlungsweisen waren noch schlechter belegt - und das betrifft auch konventionelle Therapieformen wie z. B. pharmakologische Ansätze. Die Autoren meinen daher, dass ein Evidenzvakuum besteht.

\section{Kommentar}

Angesichts der Häufigkeit und des hohen Leidensdrucks des Schwangerschaftserbrechens, ist dieser eklatante Mangel an Studien bemerkenswert. Medikamente werden aus verständlichen Gründen nur mit größter Zurückhaltung angeboten. Nicht medikamentöse Verfahren wären daher angebracht, aber auch sie sind kaum untersucht. Auch heute noch sind Forscher meist männlichen Geschlechts. Ich frage mich, ob die $D a-$ tenlage ebenso dünn wäre, wenn wir Männer an Schwangerschaftserbrechen zu leiden hätten?

E. ERNST -

- A. Matthews et al.

Interventions for nausea and vomiting in early pregnancy. Cochrane Database Syst. Rev. 2010; (9) CDoo7575. 